\title{
Measurement of Oral Medicine Learning Motivation in Dental Students Using Indonesian Version of Science Motivation Questionnaire II (SMQ-II)
}

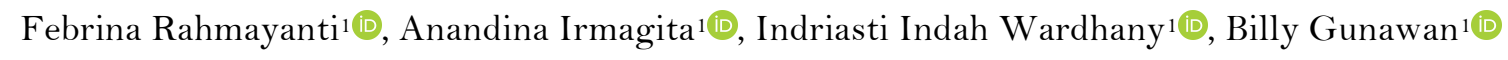

${ }^{1}$ Oral Medicine Department, Faculty of Dentistry, Universitas Indonesia, Jakarta, Indonesia.

Author to whom correspondence should be addressed: Febrina Rahmayanti, Oral Medicine Department, Faculty of Dentistry, Universitas Indonesia, Jakarta, 10430, Indonesia. Phone: +62-811131329. E-mail: febrina_r@ui.ac.id.

Academic Editors: Alessandro Leite Cavalcanti and Wilton Wilney Nascimento Padilha

Received: 29 December 2019 / Accepted: 14 June 2020 / Published: 13 July 2020

How to cite this article: Rahmayanti F, Irmagita A, Wardhany II, Gunawan B. Measurement of oral medicine learning motivation in dental students using Indonesian version of Science Motivation Questionnaire II (SMQ-II). Pesqui Bras Odontopediatria Clín Integr. 2020; 20:e5486. https://doi.org/10.1590/pboci.2020.136

\footnotetext{
Abstract

Objective: To assess the learning motivation level in Oral Medicine (OM) among Universitas Indonesia dental students. Material and Methods: This research used an analytic-descriptive study with a crosssectional design by gathering data directly from total population of Universitas Indonesia dental students. Participants were divided into three groups based on curriculum: G1: pre-clinical who have not had OM, G2: pre-clinical who had taken OM, and G3: clinical years. Data gathering was using Science Motivation Questionnaire II (SMQ-II), which include five motivation components: intrinsic motivation, self-efficacy, self-determination, grade motivation and career motivation. Results: The response rate of this study was 96.6\% (743 subjects). The Intraclass Correlation Coefficient of 0.941 indicated good internal consistency. In discriminant validity test, grade motivation and career motivation of pre-clinical groups showed no significant difference. Among three, G3 acquired the highest mean score for highly motivated groups (67.27), followed by G2 (65.89), ended by G1 (62.54). The highest mean score for overall motivation, acquired by G3. Conclusion: Clinical years group have the highest motivation level to learn in Oral Medicine.

Keywords: Behavior and Behavior Mechanisms; Learning; Students, Dental.
} 


\section{Introduction}

Motivation is an internal state that enhances, directs, and maintains an attitude of oneself [1]. Motivation is also considered as a multi-dimensional construct that interacts with cognitive in learning [2], a continuous process that can be affected by changes in attitude. Intrinsic factors, such as motivation, mental characteristics, emotional traits, and a particular goal to achieve, could also affect the learning process [3].

Indonesia is facing oral and dental health problems that keep on increasing annually. According to Indonesia Basic Health Research (RISKESDAS) in 2013, from 2007-2013, there is a 2.7\% increase of people who faced oral and dental health problems (from 23.2\% to 25.9\%) [4], that also includes lesions of oral soft tissue. These issues are becoming a major concern in dentistry, where a dentist is required to master the ability to diagnose and treat oral soft tissue lesions, which are further studied in Oral Medicine (OM) field [5].

Therefore, a dentist is encouraged to learn more in Oral Medicine and to be motivated to do it. Consequently, it is necessary to study more about dental students learning motivation towards Oral Medicine.

\section{Material and Methods}

Study Design and Sample

This research is an analytical descriptive study with a cross-sectional design. The participants of this study were the dental students Universitas Indonesia in Depok and Salemba.

\section{Data Collection}

Participants were divided into three groups: G1: pre-clinical who have not had OM; G2: pre-clinical who had taken OM; and G3: clinical years. Data collection of this study used a google form-based questionnaire. The instrument used the Indonesian version of the Science Motivation Questionnaire II (SMQII).

Science Motivation Questionnaire II (SMQ-II) is an instrument used to measure a person's level of motivation to learn. SMQ-II has undergone a revision from SMQ to adjust to the development of social conditions. A Likert scale measures the level of motivation. It will measure five components of motivation, such as intrinsic motivation, self-determination, self-efficacy, career motivation, and grade motivation [6]. This questionnaire has been through cross-cultural adaptation to form the Indonesian version [7]. In this study, the word "science" was replaced by "OM" to get results related to its purpose.

\section{Data Analysis}

The Statistical Package for the Social Sciences (SPSS), version 22 (SPSS Inc., Chicago, Illinois, USA) was used. The internal consistency test used the Intraclass Correlation Coefficient (ICC) test and the results were tested by discriminant validity using dichotomous global questions to distinguish groups of high and low motivated students. The results were compared between groups ( 1 vs. 2 and 2 vs. 3 ).

Ethical Considerations

This research protocol was approved by the Ethics Committee of the Faculty of Dentistry, Universitas Indonesia (Protocol No. 010910818 ).

\section{Results}


The total subject who was targeted to fulfill the questionnaire was 769 , but only 743 who completed all (96.6\%). Table 1 shows sociodemography characteristics. The majority of participants consisted of women $(84.4 \%)$ and the age ranged from 16 to 27 years (median 21 years).

\begin{tabular}{lc} 
Table 1. Distribution of students according to demographic characteristics. \\
\hline \multicolumn{1}{c}{ Variables } & N (\%) \\
\hline Gender & $630(84.4)$ \\
Female & $113(15.2)$ \\
Male & \\
Age (in Years) & $20.73( \pm 2.03)$ \\
Mean (SD) & $352(47.4)$ \\
$16-20$ & $387(52.1)$ \\
$21-25$ & $4(0.6)$ \\
$>25$ & $124(16.7)$ \\
Class of (Based on Year of Enrolled) & $123(16.6)$ \\
2018 & $113(15.2)$ \\
2017 & $110(14.8)$ \\
2016 & $273(36.7)$ \\
2015 & \\
$2009-2014$ & $237(31.9)$ \\
Group & $233(31.4)$ \\
G1 (2016 and 2018) & $273(36.7)$ \\
G 2 (2015 and 2017) &
\end{tabular}

Cronbach's Alpha was 0.941. The result of internal consistency from each group shows excellent agreement. The value of Cronbach's Alpha from the internal consistency test on each group's motivational components can be viewed in Table 2 .

Tabel 2. Analysis of motivational components internal consistency.

\begin{tabular}{cc}
\hline Groups & Cronbach's Alpha* \\
\hline G1 & 0.955 \\
G2 & 0.936 \\
G3 & 0.918 \\
Total Score & 0.941 \\
\hline
\end{tabular}

*Measured with Intraclass Correlation Coefficient (ICC) test.

The Science Motivation Questionnaire-II (SMQ-II) questionnaire about Oral Medicine was necessary to undergo a validity discriminant test. All study participants were required to select "yes" or "no" to the statement "I achieved good grades on my Oral Medicine Course". The result of G1 shows no significant difference $(\mathrm{p} \geq 0.05)$ in grade motivation component, whereas other component shows significant differences. The result of G2 shows no significant difference in career motivation component, whereas other component shows significant differences. Besides these two components, the rest of motivational components domain shows good validity discriminant results. The results of validity discriminant test can be viewed on Table 3 .

Table 3. Discriminant validity from Science Motivation Questionnaire-II (SMQ-II).

\begin{tabular}{|c|c|c|}
\hline Groups & Domain & p-value \\
\hline G1 & Intrinsic Motivation & 0.000 \\
\hline & Self-Efficacy & 0.001 \\
\hline
\end{tabular}




\begin{tabular}{llc} 
& Self-Determination & 0.002 \\
& Grade Motivation & $0.067^{*}$ \\
G2 & Toreer Motivation & 0.004 \\
& Intrinsic Motivation & 0.000 \\
& Self-Efficacy & 0.000 \\
Self-Determination & 0.000 \\
Grade Motivation & 0.005 \\
Career Motivation & Total Score & 0.000 \\
& Intrinsic Motivation & $0.148^{*}$ \\
Self-Efficacy & 0.000 \\
Self-Determination & 0.000 \\
Grade Motivation & 0.000 \\
Career Motivation & 0.011 \\
& Total Score & 0.014 \\
\hline
\end{tabular}

*Mann-Whitney U-test.

Table 4 shows the frequency distribution of the characteristics of each component of learning motivation towards Oral Medicine, based on SMQ-II. In G1 and G3, all data in each domain showed abnormal data distribution results. In contrast to that, the results of the total score in G2 shows a normal data distribution results, whereas the rest of motivational components show abnormal data distribution results.

Table 4. Descriptive statistics of each motivational components.

\begin{tabular}{lccc}
\hline \multicolumn{1}{c}{ Domains } & Groups & Median* & Mean (SD) \\
\hline Intrinsic Motivation & G1 & 12.0 & $11.32( \pm 4.10)$ \\
Self-Efficacy & G2 & 11.0 & $11.45( \pm 3.43)$ \\
& G3 & 12.0 & $12.29( \pm 2.78)$ \\
Self-Determination & G1 & 12.5 & $12.40( \pm 4.49)$ \\
& G2 & 11.0 & $11.82( \pm 3.78)$ \\
Grade Motivation & G1 & 12.0 & $11.75( \pm 2.90)$ \\
& G2 & 11.0 & $10.62( \pm 5.09)$ \\
Career Motivation & G3 & 12.0 & $12.52( \pm 3.73)$ \\
& G1 & 14.0 & $13.67( \pm 2.49)$ \\
Total Score & G2 & 14.0 & $13.65( \pm 4.31)$ \\
& G3 & 14.0 & $13.69( \pm 3.52)$ \\
& G1 & 14.0 & $13.83( \pm 2.94)$ \\
& G2 & 14.0 & $13.33( \pm 3.97)$ \\
& G3 & 14.0 & $13.91( \pm 3.70)$ \\
& G1 & 14.0 & $13.77( \pm 2.88)$ \\
& G2 & 63.0 & $61.32( \pm 19.08)$ \\
\hline
\end{tabular}

*Minimum $=0$ and Maximum $=20$

Table 5 shows a comparison between Groups 1 and 2 and no significant differences in intrinsic motivation, grade motivation, career motivation and total score were found. Whereas, there were significant differences in the components of self-efficacy and self-determination.

Table 6 shows a comparison between Groups 2 and 3. The comparison results show no significant differences in motivational components of self-efficacy, grade motivation, career motivation, and total score. But, there are significant differences in motivational components of intrinsic motivation and self-determination. 
Table 5. Analysis of comparison between groups 1 and 2.

\begin{tabular}{lc}
\multicolumn{1}{c}{ Domains } & p-value \\
\hline Intrinsic Motivation & 0.992 \\
Self-Efficacy & $0.028^{*}$ \\
Self-Determination & $0.000^{*}$ \\
Grade Motivation & 0.336 \\
Career Motivation & 0.094 \\
\multicolumn{1}{c}{ Total Score } & 0.498 \\
\hline *Mann-Whitney U-test.
\end{tabular}

Tabel 6. Analysis of comparison between groups 2 and 3.

\begin{tabular}{lc}
\hline \multicolumn{1}{c}{ Domains } & p-value \\
\hline Intrinsic Motivation & $0.013^{*}$ \\
Self-Efficacy & 0.710 \\
Self-Determination & $0.001^{*}$ \\
Grade Motivation & 0.746 \\
Career Motivation & 0.326 \\
\multicolumn{1}{c}{ Total Score } & 0.174 \\
\hline
\end{tabular}

\section{Discussion}

This study took participants from the total active Dental Students Universitas Indonesia population. The response rate of this study reached 96.6\%. The majority of the participants consisted of women (84.4\%) and this was consistent with the overall proportion in the student population. This is in line with previous results that showed that the number of women who dominate in the field of dentistry is an increasing trend in the last 40 years [8]. The age category in this study was divided into three parts. The first part is age group, from 21 to 25 years of the total population (52.1\%). The second-highest number of age group respondent, range from 16 to 20 years $(47.4 \%)$ and last is age group above 25 years (0.6\%). It can occur because it relates to the study period taken during pre-clinical years and clinical years. Dental students undergo a pre-clinical period for 3.5 years; hence age of students generally ranges from 17 to 21 years. While the clinical period is taken for 2 years, hence age of students generally ranges from 21 to 23 years [9]. Populations over the age of 25 years indicate that there are students who still experience problems in completing the clinical study period.

In grade motivation component of Group 1 (Pre-Clinical hadn't had OM), Indonesian version of SMQII has not distinguished groups of students with high and low motivation. This is in line with the theory of extrinsic motivation components regarding particular behavior that is formed due to the existence of rewards that can be achieved at the end [10]. Group 1 is still difficult to determine motivation in learning OM with the results of getting good grades because they are not yet in a position where seeing good grade deserves to be achieved. In Group 2 (Pre-Clinical taken OM), Indonesian version of SMQ-II has not distinguished those who are motivated to learn OM related to careers. Previous authors have demonstrated that pre-clinical students are still at the stage of prioritizing academic achievement more than providing health services for public [11].

In components of intrinsic motivation, self-efficacy, self-determination and total score, the discriminant validity test is able to distinguish between students with high and low learning motivation towards OM. This is consistent with the theory stated that intrinsic motivation is closely related to selfefficacy [12]. This validity test is also valid in self-determination component as it can be seen from a group of 
students who have a high interest in a lesson. It indicates a high level of self-determination from the students' perspective [13].

Bivariate comparison analysis was used to see whether there are differences in learning motivation levels between two groups. A comparison of learning motivation towards OM between Groups 1 and 2 was conducted because there were similarities among these groups in terms of academic system being pursued. A comparison of learning motivation towards OM between Groups 2 and 3 was done because they have similarities in terms of $\mathrm{OM}$ course that has been taken during the pre-clinical period. While the comparison between Groups 1 and 3 was not conducted due to unequal differences of $\mathrm{OM}$ course exposure. The comparison analysis results between Groups 1 and 2 show significant differences in motivational components of self-efficacy and self-determination $(\mathrm{p}<0.05)$. Self-efficacy of Group 1 was higher compared to Group 2 . It is consistent with previous findings that showed that self-efficacy is closely related to the level of anxiety. It suggests that if a person's anxiety level is high, then the level of self-efficacy decreases [14]. Furthermore, the level of self-determination of Group 2 had higher results. It is in line with a previous study that demonstrated that a learning behavior could be formed if they believe they have control over their own choice of learning $[15]$.

On the other side, motivational components of intrinsic motivation, grade motivation, career motivation, and total score of these two groups show no significant differences $(\mathrm{p} \geq 0.05)$. In intrinsic motivation component, Group 2 had a higher result compared to Group 1. Previous authors stated that the increase in students' motivation and interest in learning are the results of effective forms of teaching [16]. This has been experienced by a group of participants who had taken OM before. In grade motivation and career motivation components, Group 2 also has a higher result and these findings are in agreement with the literature that demonstrates that an increase in extrinsic motivation also means there is a corresponding increase in grade and career motivation [6]. In the total score domain, Group 2 has a higher result compared to Group 1. This is related to internalization process theory stating that behavior regulated continuously, with various didactic-methodical approaches to education and teaching, can change something external in origin, into something more acceptable internally [17].

This study also analyzed a comparison between Groups 2 and 3. These groups show significant differences in intrinsic motivation and self-determination components $(\mathrm{p}<0.05)$. Group 3 shows a higher result in intrinsic motivation component compared to Group 2. According to previous authors, an increase in intrinsic motivation can occur because clinical students have experienced a more effective form of teaching due to direct interaction between doctors-patients [16]. Looking at self-determination component, Group 3 also scores higher compared to Group 2. It is in alignment with the increase in intrinsic motivation that will also affect an increase in self-determination component. It is supported by theory and comparative selfdetermination study, which states that certain behavior can arise due to the belief that someone has control over an act of learning, which begins from intrinsic motivation [12,15]. In self-efficacy, grade motivation, career motivation, and total score of these two groups show no significant differences ( $\mathrm{p} \geq 0.05)$. But looking at the mean result, Group 2 has a higher result of self-efficacy component compared to Group 3. It has been reported that an increase in student anxiety levels also has an impact on students' self-efficacy [18]. Viewing at grade motivation component, Group 3 has higher results due to certain goals to achieve, which are related to graduating on time and making them motivated to get good grades.

Looking at career motivation, there was a difference compared to the previous increase. Group 2 has a higher result compared to Group 3. This is despite conflicting with a previous extrinsic motivation theory. It is 
supported by a previous study that stated that self-efficacy might influence someone's goals, including career, which in turn makes someone more focused on his choices [19,20]. Furthermore, viewing at total score, Group 3 has a higher result compared to Group 2. This is again related to internalization process theory, which states that a behavior regulated continuously, with various didactic-methodical approaches to education and teaching, can change something external in origin into something more acceptable internally [17].

\section{Conclusion}

The three groups of participants had a higher group of highly motivated learning compared to those who had low learning motivation towards OM. In career motivation component, Group 2 has the highest result among other two groups. In self-efficacy component, Group 1 has the highest result compared to others. In intrinsic motivation component, self-determination, grade motivation, and overall total score, Group 3 has the highest result compare to other two groups.

\section{Authors' Contributions}

\begin{tabular}{|c|c|c|}
\hline FR & (iD) $0000-0002-9918-1571$ & $\begin{array}{l}\text { Writing - Original Draft Preparation, Writing - Review and Editing, Supervision } \\
\text { and Project Administration. }\end{array}$ \\
\hline AI & (iD) $0000-0001-9253-2810$ & Conceptualization, Methodology and Supervision. \\
\hline IIW & (iD) $0000-0003-4154-4111$ & Conceptualization, Methodology, Writing - Review and Editing and Supervision. \\
\hline BG & (iD) 0000-0001-7423-2005 & Investigation, Formal Analysis and Writing - Review and Editing. \\
\hline
\end{tabular}

\section{Financial Support}

Universitas Indonesia Research Grant (Hibah PITTA 2019), No.NKB-0567/UN2.R3.1/HKP.05.00/2019).

\section{Conflict of Interest}

The authors declare no conflicts of interest.

\section{References}

[1] Glynn SM, Taasoobshirazi G, Brickman P. Nonscience majors learning science: a theoretical model of motivation. J Res Sci Teach 2007; 44(8):1088-1107.

[Q] Salta K, Koulougliotis D. Assessing motivation to learn chemistry: adaptation and validation of Science Motivation Questionnaire II with Greek secondary school students. Chem Educ Res Pr 2015; 16(2):237-50

[3] Mirzazad S, Vosoughhosseini S, Khodadoust K, Emamverdizadeh P. Factors affecting learning in theoretical and practical oral pathology courses among dental students at Tabriz University of Medical Sciences. Int J Sci Res Innov Technol 2017; 4(7):33-41.

[4] Pusat Data dan Informasi - Kementerian Kesehatan RI. Situasi Kesehatan Gigi dan Mulut. Laporan Hasil Riset Kesehatan Dasar. 2014. p. 1-4. [In Indonesian].

[5] Kondori I, Mottin RW, Laskin DM. Accuracy of dentists in the clinical diagnosis of oral lesions. Quintessence Int $2011 ; 42(7): 575-7$.

[6] Glynn SM, Brickman P, Armstrong N, Taasoobshirazi G. Science motivation questionnaire II: validation with science majors and nonscience majors. J Res Sci Teach 2011; 48(10):1159-76. https://doi.org/10.1002/tea.20442

[7] Wardhany II, Subita GP, Maharani DA. Cross-cultural adaptation and psychometric properties of the Science Motivation Questionnaire-II: Indonesian version. Pesqui Bras Odontopediatria Clin Integr 2018; 18(1):e4294. https://doi.org/10.4034/PBOCI.2018.181.111

[8] Mckay, JC, Quinonez CR. The feminization of dentistry: implications for the profession. J Can Dent Assoc 2012; 78:c1.

[9] Faculty of Dentistry. Academic Stage. Available from: http://fkg.ui.ac.id/academics/academic-stage. [Accessed on July 20, 2019]. 
[10] Mehralizadeh S, Pourhoseini M, Vakili A, Ghorbani R, Zolfaghary S. Factors affecting learning of anatomy: students' viewpoints. Iran J Med Educ 2013; 13(1):49-57.

[11] Crossley ML, Mubarik A. A comparative investigation of dental and medical student's motivation towards career choice. Br Dent J 2002; 193(8):471-3. https://doi.org/10.1038/sj.bdj.4801599

[12] Kusurkar RA, Croiset G, Galindo-Garré F, Ten Cate O. Motivational profiles of medical students: association with study effort, academic performance and exhaustion. BMC Med Educ 2013; 13:87. https://doi.org/10.1186/1472-6920-13-87

[13] Vansteenkiste M, Sierens E, Soenens B, Luyckx K, Lens W. Motivational profiles from a self-determination perspective: the quality of motivation matters. J Educ Psychol 2009; 101(3):671-88. https://doi.org/10.1037/a0015083

[14] Cassady JC, Johnson RE. Cognitive test anxiety and academic performance. Contemp Educ Psychol 2002; 27(2):27095. https://doi.org/10.1006/ceps.2001.1094

[15] Black AE, Deci EL. The effects of instructors' autonomy support and students' autonomous motivation on learning organic chemistry: a self-determination theory perspective. Sci Ed 2000; 84:740-56.

[16] Gump SE. Keep students coming by keeping them interested: motivators for class attendance. Coll Stud J 2004; 38(1):157-60.

[17] Mulyana R. Mengartikulasikan Pendidikan Nilai. Bandung: Alfabeta; 2004. [In Indonesian].

[18] Glynn SM, Koballa T. R. Motivation to Learn in College Science. In: Mintzes JJ, Leonard WH. Handbook of College Science Teaching. Arlington: National Science Teachers Association Press; 2006. p. 25-32.

[19] Bong M. Academic motivation in self-efficacy, task value, achievement goal orientations, and attributional beliefs. J Educ Res 2004; 97(6):287-98. https://doi.org/10.3200/JOER.97.6.287-298

[20] Chemers MM, Hu L, Garcia BF. Academic self-efficacy and first-year college student performance and adjustment. J Educ Psychol 2001; 93(1):55-64. https://doi.org/10.1037//0022-0663.93.1.55 